\title{
A concurrent validity study of the Wechsler Preschool and Primary Scale of Intelligence-Revised and Columbia Mental Maturity Scale
}

\author{
HOWARD H. CARVAJAL, CHERRI S. PARKS, JAMES P. PARKS, \\ ROBERT A. LOGAN, and GREGORY L. PAGE \\ Emporia State University, Emporia, Kansas
}

(Stephen F. Davis, Sponsor)

\begin{abstract}
The Wechsler Preschool and Primary Scale of Intelligence-Revised and the Columbia Mental Maturity Scale were given to 51 preschool, kindergarten, first-, and second-grade students. Although two of three Pearson correlations between the two tests were statistically significant, they may not be of practical significance. It is not recommended that the Columbia be substituted for the Wechsler.
\end{abstract}

The recent federal mandate for implementation of early childhood handicapped programs (Public Law 99-457) requires an appraisal of children's intellect. The use of screening tests could be employed to determine which children need to have a more thorough evaluation. Although screening tests are brief, ordinarily they can provide relatively accurate and meaningful data conveniently, enabling psychologists and others to determine if additional testing is necessary. Prior to their use, however, their validity must be established. One of the methods of determining the validity of screening tests of intelligence is by establishing their concurrent validity with the Stanford-Binet IV or with one of the Wechsler series of tests. One of the methods of determining concurrent validity is to administer a test that has been proved valid (e.g., the Wechsler) in addition to administering the other instrument (i.e., the screening test) and to find the relationship or correlation between the two tests.

The new Wechsler Preschool and Primary Scale of Intelligence-Revised (WPPSI-R; Wechsler, 1989) may occupy a more prominent role than that of its predecessor, the WPPSI (Wechsler, 1967), because of the emphasis now being placed on early childhood evaluations. Major differences between the 1967 WPPSI and the WPPSI-R are the following: (1) the expansion of the age range to include 3-year-old children, as well as those up to 7 years and 3 months, (2) a new subtest (object assembly), and (3) numerous item changes that make the test appropriate for the new age range and update the items and improve their quality.

Correspondence should be addressed to H. H. Carvajal, Division of Psychology, Emporia State University, 1200 Commercial, Emporia, KS 66801-5087.
One of the screening tests of intelligence in use today is the Columbia Mental Maturity Scale (CMMS; Burgemeister, Blum, \& Lorge, 1972); it saves time and yields reliable and valid data. Kaufman (1978) declared that the CMMS "is undoubtedly the best brief instrument (verbal or nonverbal) available, and it ranks as one of the finest for assessing preschool children" (p. 301). Salvia and Ysseldyke (1991) stated that the CMMS "is adequately standardized and appears technically adequate" and was designed for "children who have difficulty responding verbally" (p. 212).

For those whose practice includes the evaluation of young children, the information concerning the relationships of the WPPSI-R with the CMMS will be of interest. Because the WPPSI-R manual does not provide correlative data involving the WPPSI-R and any screening devices, the present study was designed to yield preliminary data on this issue. Specifically, an answer to the following question was sought: What are the relationships between the WPPSI-R Verbal (V), Performance (P), and Full Scale (FS) IQs and the CMMS Age Deviation Scores (ADS)?

\section{METHOD}

\section{Participants}

Approximately 80 letters were sent to the parents of children whose ages fell in the WPPSI-R range ( 3 years to 7 years, 3 months) and who were enrolled in preschool, kindergarten, first, or second grade in an elementary school in a midwestern community of 27,000 . Fifty-one children ( 27 boys, 24 girls) whose parents signed permission forms and who ranged in age from 3 years, 6 months to 7 years, 3 months $(M=$ $5.7 ; S D=1.0$ ) were tested with the WPPSI-R and the CMMS. With the exception of one Hispanic boy and one Chinese-American boy, all of the children were Caucasian and would be considered middle class.

Tests

The complete WPPSI-R battery was given. It yields V, P, and FS IQs, which have a mean of 100 and a standard deviation of 15 . The 
Table 1

Descriptive Statistics

\begin{tabular}{lcc}
\hline \multicolumn{1}{c}{ Test } & $M$ & $S D$ \\
\hline WPPSI-R Verbal IQ & 107.6 & 14.4 \\
WPPSI-R Performance IQ & 108.8 & 13.2 \\
WPPSI-R Full Scale IQ & 109.5 & 14.0 \\
CMMS Age Deviation Score & 110.5 & 9.5 \\
\hline
\end{tabular}

CMMS items that were appropriate for each child's age were administered. The mean and standard deviation of the CMMS ADS were 100 and 16 , respectively.

\section{Procedure}

Two second-year graduate students who had successfully completed the appropriate testing course in their clinical psychology programs and one faculty member administered the tests in a counterbalanced sequence between October 1 and December 14, 1990. All tests were given under standard conditions, and standardized procedures were followed.

\section{RESULTS}

The obtained means for the WPPSI-R IQs and the CMMS ADS were greater than those of the norm groups. Although the norms for the two tests were developed almost 20 years apart, the means were virtually identical. The standard deviation of the CMMS was smaller than that of the norm group. Those of the Wechsler IQs were about the same as the normative sample. These descriptive measures are shown in Table 1 .

Because the size of the standard deviations of the two tests are different, for meaningful comparisons the scores of each test were converted to $z$ scores by utilizing the means and standard deviations of the normative samples. A 2 (gender) $\times 4$ (test) repeated measures analysis of variance was performed on the $z$ scores. Gender was the between-subject variable, and test was the within-subject variable. A statistically significant difference was observed for the test $\times$ gender interaction $[F(3,147)=4.53$, $p<.05$ ].

The three WPPSI-R $z$ scores and the CMMS $z$ scores were then individually compared by using the Bonferoni procedure. No statistically significant differences were found.

The Pearson product-moment correlations between the CMMS ADS and the WPPSI-R V, P, and FS IQs were $.18, .49$, and .37 , respectively. The correlations involving the P and FS IQs were statistically significant $(p<$ $.01)$.

\section{DISCUSSION}

Although two of the correlations were statistically significant, the value of the correlations may be too low to be of practical significance; one would not be able to predict the WPPSI-R FS IQ accurately from the CMMS score. A higher correlation between the WPPSI-R P IQ and the CMMS ADS was expected because the CMMS is a nonverbal test and its content more closely resembles that of the Performance portion of the WPPSI-R than that of the Verbal section. Although the correlation of .49 between the WPPSI-R P IQ and the CMMS ADS may be marginally helpful, it may not be sufficiently high to be useful in predicting WPPSI-R scores.

The correlation between the WPPSI revision and the CMMS is lower than the correlation found between the 1967 WPPSI and the CMMS in earlier studies that used children from the same school. Using data extracted from Carvajal, Hardy, Harmon, Sellers, and Holmes (1987) and Carvajal, Hardy, Smith, and Weaver (1988), a kindergarten class from the same school as the children in the current study had a correlation of .52 between the 1967 WPPSI FS IQ and the CMMS.

Among the factors that may have contributed to the low FS IQ and CMMS correlation found in the current study was the large percentage (39\%) of preschool children tested. The younger the child, the greater the possibility that some external factor(s) may affect a child's performance.

An issue apart from this study that must be addressed by the author and publisher of the CMMS is the age of the CMMS norms (20 years). Are these norms still accurate, or should they be updated?

In addition, studies must be conducted with children of a variety of ages and types prior to using the CMMS as a screening test in place of the WPPSI-R. Until additional information has been obtained, it is not recommended that one use the CMMS for screening.

\section{REFERENCES}

Burgemeister, B. B., Blum, L. H., \& Lorge, I. (1972). Guide for administering and interpreting the Columbia Mental Maturity Scale (3rd ed.). New York: Harcourt Brace Jovanovich.

Carvajal, H. H., Hardy, K., Harmon, K., Sellers, T. A., \& Holmes, C. B. (1987). Relationships among scores on the StanfordBinet IV, Peabody Picture Vocabulary Test-Revised, and Columbia Mental Maturity Scale. Bulletin of the Psychonomic Society, 25, 275-276.

Carvajal, H. H., Hardy, K., Smith, K. L., \& Weaver, K. A. (1988). Relationships between scores on Stanford-Binet IV and Wechsler Preschool and Primary Scale of Intelligence. Psychology in the Schools, 25, 129-131.

Kaufman, A. S. (1978). Review of the Columbia Mental Maturity Scale. In O. Buros (Ed.), The eighth mental measurements yearbook (pp. 299301). Highland Park, NJ: Gryphon.

Salvia, J. A., \& YsseldyKe, J. E. (1991). Assessment (5th ed.). Boston: Houghton Mifflin.

WeChSLER, D. (1967). Manual for the Wechsler Preschool and Primary Scale of Intelligence. New York: Psychological Corporation.

WeChSLER, D. (1989). Manual for the Wechsler Preschool and Primary Scale of Intelligence-Revised. San Antonio: Psychological Corporation. 